\title{
An isolated elevation in blood urea level is not 'uraemia' and not an indication for renal replacement therapy in the ICU
}

\author{
Jack Mackenzie $^{1}$ and Bobby Chacko ${ }^{1,2^{*}}$ (i)
}

\begin{abstract}
The decision to initiate renal replacement therapy (RRT) and the optimal timing for commencement is a difficult decision faced by clinicians when treating acute kidney injury (AKI) in the intensive care setting. Without clinically significant ureamic symptoms or emergent indications (electrolyte abnormalities, volume overload) the timing of RRT initiation remains contentious and inconsistent across health providers. Current trends of initiating RRT in the ICU are often based on isolated blood urea levels without clear guidelines demonstrating an upper limit for treatment. Although the appropriate upper limit remains unclear, it is reasonable to conclude that a blood urea level less than $40 \mathrm{mmol} / \mathrm{L}$ is not in itself an indication for RRT, especially in the absence of supporting evidence of kidney impairment (anuria, elevated serum creatinine), presenting a welcome reminder to treat the patient and not a number.
\end{abstract}

Keywords: Uraemia, RRT, ICU

\section{Introduction}

The decision to initiate renal replacement therapy (RRT) and the optimal timing for commencement is a difficult decision clinicians face when treating acute kidney injury (AKI) in the intensive care setting. Without clinically significant ureamic symptoms or emergent indications (electrolyte abnormalities, volume overload) the timing of RRT initiation remains contentious and inconsistent across health providers. The issue is further complicated by several randomised control trials (RCTs)

\footnotetext{
* Correspondence: Bobby.Chacko@hnehealth.nsw.gov.au

${ }^{1}$ School of Medicine and Public Health, University of Newcastle, Newcastle, NSW, Australia

${ }^{2}$ Nephrology and Transplantation Unit, John Hunter Hospital, Newcastle, NSW 2310, Australia
}

C The Author(s). 2017 Open Access This article is distributed under the terms of the Creative Commons Attribution 4.0 International License (http://creativecommons.org/licenses/by/4.0/), which permits unrestricted use, distribution, and reproduction in any medium, provided you give appropriate credit to the original author(s) and the source, provide a link to the Creative Commons license, and indicate if changes were made. The Creative Commons Public Domain Dedication waiver (http://creativecommons.org/publicdomain/zero/1.0/) applies to the data made available in this article, unless otherwise stated.

\section{Discussion}

Despite early meta-analysis suggesting early RRT improves survival in critical illness [7], more recent analysis does not support that view $[8,9]$. The most comprehensive data regarding optimal timing for RRT initiation comes from a 2017 meta-analysis of RCTs assessing early versus late initiation of RRT in patients with AKI [8] that concluded there was no added benefit of early initiation with respect to 30,60 , and 90-day mortality, overall ICU and hospital mortality, and dialysis dependence. Older studies have demonstrated increased mortality when serum urea reaches higher ranges $(50.7-71.4 \mathrm{mmol} / \mathrm{L})$ [10], which perhaps established the tendency to initiate RRT therapy at lower levels.

Evaluation of the available data led to the proposal of serum urea $>35.7 \mathrm{mmol} / \mathrm{L}$ as an absolute indication for RRT [11] but no recent RCTs have looked at urea as an independent variable for initiation. The only study found to consider serum urea in isolation confirmed a declining trend of threshold urea level for RRT initiation and no association with in-hospital mortality [12]. Most 
recent studies did, however, implement an upper limit at which interventional RRT was initiated Table 1.

As no recent RCTs assess urea independently, it is reasonable to extrapolate the correlating urea levels to make a plausible appraisal of what level is acceptable to commence RRT. The recently examined upper limit was $>35.7 \mathrm{mmol} / \mathrm{L}$ to the onset of clinical signs or symptoms, although most studies initiated treatment no higher than $40 \mathrm{mmol} / \mathrm{L}$. With evidence that no added benefit is derived from early therapy, in the absence of emergent indications a serum urea level of $40 \mathrm{mmol} / \mathrm{L}$ is therefore not unreasonable.

The practical implications are balancing the theoretical assumption that early initiation of RRT may lead to earlier removal of uraemic toxins, against the possibility that delayed treatment may result in spontaneous recovery and avoidance of RRT entirely. The KDIGO guidelines conclude that it is unclear whether the risks outweigh the benefits and that RRT should be initiated emergently when life threatening changes in fluid, electrolyte and acid-base balance exist [7]. Furthermore, it recommends considering the broader clinical context, the presence of modifiable conditions and trends of laboratory tests rather than serum urea and creatinine thresholds alone [7].

Without definitive guidelines, there is sufficient evidence to suggest that initiation of RRT in a patient with a urea level less than $40 \mathrm{mmol} / \mathrm{L}$ in an otherwise stable clinical context is erroneously exposing them to risks of dialysis without any increased survival benefit. Furthermore, a reasonable argument can be made that even above $40 \mathrm{mmol} / \mathrm{L}$, delaying RRT may be warranted in an otherwise clinically well patient with preserved kidney function.

Correlating clinical symptoms with blood urea levels in the ICU to aid the decision to commence RRT is complicated by many factors that have been identified as contributors to elevated urea levels such as dehydration, increased tubular urea reabsorption, heart failure, glucocorticoid use, gastrointestinal haemorrhage and exogenous protein sources (dietary intake,
PEG feeds and colloids). At moderate serum urea levels $(21.4 \mathrm{mmol} / \mathrm{L})$ these factors do not appear to elicit ureamic symptoms in isolation from severely impaired kidney function [13].

Despite reliance on historical data and lack of recent quality evidence, it is plausible that, in the context of established kidney injury, the onset of ureamic symptoms is likely when the blood urea level is greater than $50 \mathrm{mmol} / \mathrm{L}$. However, given the poor correlation with clinical symptoms, the multifactorial nature of AKI and variation in production and excretion, serum urea alone remains a poor indicator of ureamic toxicity, especially in the presence of additional urea-elevating factors, or the absence of other symptomatic or biochemical markers of severe kidney impairment.

\section{Conclusions}

Currently there is no well-established upper-limit of serum urea that serves as an indication for initiation of RRT in AKI. Using urea in isolation is difficult and potentially flawed given the variation in base level and production rates amongst different populations as well as it's negligibility as an accurate measure of metabolite toxicity. Furthermore, AKI is a multifactorial condition and it is likely to present earlier with other concerning metabolic or fluid overload abnormalities requiring dialysis rather than isolated elevated blood urea levels. Studies have considered the appropriate timing of initial RRT including early and delayed/late commencement of therapy, with a recent meta-analysis concluding there is no added benefit. Most studies initiated RRT once blood urea level exceeded $40 \mathrm{mmol} / \mathrm{L}$, which is reflected in clinical practice despite evidence to suggest it does not correlate well with onset of uraemic symptoms.

Although the appropriate upper limit remains unclear, it is reasonable to conclude that a blood urea level less than $40 \mathrm{mmol} / \mathrm{L}$ is not in itself an indication for RRT therapy, especially in the absence of supporting evidence of kidney impairment (anuria, elevated serum creatinine), presenting a welcome reminder to treat the patient and not a number.

Table 1 Collation of recent studies with blood urea level criteria in exclusion or intervention

\begin{tabular}{|c|c|c|c|}
\hline Study & Year & Urea exclusion criteria & Late RRT urea intervention threshold \\
\hline Zarbock et al. [5] & 2016 & None & Serum urea $>100 \mathrm{mg} / \mathrm{dL}(35.7 \mathrm{mmol} / \mathrm{L})$ \\
\hline Gaudry et al. [3] & 2016 & Urea blood > 112 mg/dL (40 mmol/L) & Urea blood > 112 mg/dL (40 mmol/L) \\
\hline Combes et al. [2] & 2015 & None & Serum urea $>36 \mathrm{mmol} / \mathrm{L}$ \\
\hline Jamale et al. [4] & 2013 & $\begin{array}{l}\text { Life-threatening uremic complications } \\
\text { (alteration of higher mental function attributable } \\
\text { to uraemia, and pericarditis) }\end{array}$ & Uremic nausea \\
\hline Bagshaw et al. [14] & 2009 & None & Serum urea $>24.2 \mathrm{mmol} / \mathrm{L}$ \\
\hline Bouman et al. [1] & 2002 & None & Serum urea $>40 \mathrm{mmol} / \mathrm{L}$ \\
\hline Pursnani et al. [15] & 1997 & Urea blood > 120 mg/dL (42.8 mmol/L) & Serum urea $>40 \mathrm{mmol} / \mathrm{L}$ \\
\hline
\end{tabular}




\section{Abbreviations}

AKl: Acute kidney injury; Cl: Confidence interval; CKD: Chronic kidney disease; ICU: Intensive care unit; KDIGO: Kidney Disease: Improving Global Outcomes; RCT: Randomised control trial; RR: Relative risk; RRT: Renal replacement therapy

\section{Acknowledgements}

Not applicable.

\section{Funding}

Not applicable.

\section{Availability of data and materia}

Not applicable.

\section{Authors' contributions}

JM was involved in analyzing and interpreting data and drafting the manuscript. BC was involved in conception and design and revising it critically for important intellectual content. Both authors read and approved the final manuscript

\section{Ethics approval and consent to participate}

Not applicable.

\section{Consent for publication}

Not applicable.

\section{Competing interests}

The authors declare that they have no competing interests.

\section{Publisher's Note}

Springer Nature remains neutral with regard to jurisdictional claims in published maps and institutional affiliations.

Received: 6 October 2017 Accepted: 23 October 2017

Published online: 13 November 2017

\section{References}

1. Bouman CS, Oudemans-Van Straaten HM, Tijssen JG, et al. Effects of early high-volume continuous venovenous hemofiltration on survival and recovery of renal function in intensive care patients with acute renal failure: a prospective, randomized trial. Crit Care Med. 2002;30:2205.

2. Combes A, Bréchot N, Amour J, et al. Early high-volume hemofiltration versus standard care for post-cardiac surgery shock. The HEROICS Study. Am J Respir Crit Care Med. 2015;192:1179.

3. Gaudry S, Hajage D, Schortgen F, et al. Initiation strategies for renal-replacement therapy in the intensive care unit. N Engl J Med. 2016;375:122.

4. Jamale TE, Hase NK, Kulkarni M, et al. Earlier-start versus usual-start dialysis in patients with community-acquired acute kidney injury: a randomized controlled trial. Am J Kidney Dis. 2013;62:1116.

5. Zarbock A, Kellum JA, Schmidt C, et al. Effect of early vs delayed initiation of renal replacement therapy on mortality in critically ill patients with acute kidney injury: the ELAIN Randomized Clinical Trial. JAMA. 2016;315:2190.

6. Kidney Disease: Improving Global Outcomes (KDIGO) Acute Kidney Injury Work Group. KDIGO clinical practice guideline for acute kidney injury. Kidney Int Suppl. 2012;2:1-138.

7. Karvellas CJ, Farhat MR, Sajjad I, Mogensen SS, Leung AA, Wald R, et al. A comparison of early versus late initiation of renal replacement therapy in critically ill patients with acute kidney injury: a systemic review and meta-analysis. Crit Care. 2011;15:R72.

8. Bhatt GC, Das RR. Early versus late initiation of renal replacement therapy in patients with acute kidney injury-a systematic review \& meta-analysis of randomized controlled trials. BMC Nephrol. 2017;18:78.

9. Lai TS, Shiao CC, Wang JJ, et al. Earlier versus later initiation of renal replacement therapy among critically ill patients with acute kidney injury: a systematic review and meta-analysis of randomized controlled trials. Ann Intensive Care. 2017;7:38

10. Nascimento GV, Gabriel DP, Abrao JM, Balbi AL. When is dialysis indicated in acute kidney injury? Ren Fail. 2010;32:396-400.

11. Gibney N, Hoste E, Burdmann EA, et al. Timing of initiation and discontinuation of renal replacement therapy in AKl: unanswered key questions. Clin J Am Soc Nephrol. 2008;3:876-880.G.
12. De Corte W, Vanholder R, Dhondt AW, et al. Serum urea concentration is probably not related to outcome in ICU patients with AKI and renal replacement therapy. Nephrol Dial Transplant. 2011;26:3211-8.

13. Meyer TW, Hostetter TH. The pathophysiology of uremia. In: Skorecki K, Chentow GM, et al., editors. Brenner and Rector's the kidney. 10th ed. Philadelphia: Elsevier Inc; 2016. p. 1807-21.

14. Bagshaw SM, Uchino S, Bellomo R, et al. Timing of renal replacement therapy and clinical outcomes in critically ill patients with severe acute kidney injury. J Crit Care. 2009;24:129-40.

15. Pursnani ML, Hazra DK, Singh B, Pandey DN. Early haemodialysis in acute tubular necrosis. J Assoc Physicians India. 1997:45:850-2. 